\title{
COBERTURAS METASSEDIMENTARES DO PROTEROZÓICO MÉDIO: OS GRUPOS ARAÍ E PARANOÁ NA REGIÃO DE NIQUELÂNDIA - COLINAS, GOIÁS
}

\author{
REINHARDT A. FUCK*, ONILDO JOÃO MARINI*, \\ MARCEL AUGUSTE DARDENNE* e ALMIR NEVES DE FIGUEIREDO*
}

\begin{abstract}
MIDDLE PROTEROZOIC METASSEDIMENTARY COVERS: ARAI AND PARANOÅ GROUPS IN THE NIQUELÂNDIA-COLINAS REGION, GOIÁS. In the Niquelândia-Colinas, Goiás, Middle Proterozoic Arấ Group nonconformably overlies granite-gneiss basement and remains of the possibly Early Proterozoic Ticunzal Formation. The Araf rocks comprise the lower Arraias Formation of quartzite, feldspathic quartzite, and metaconglomerate, and the upper Trafras Formation of carbonatic metapelite, calcschist, chlorite schist, and marble lenses, bearing greenschist facies mineral parageneses. Proeminent deformation structures are the domal shape outlined by the structural high of basement rocks and the large $5-20^{\circ} \mathrm{S} 20 \mathrm{~W}$ plunging asymmetric folds. The latter have not been recognized within the younger Paranoa Group metasediments which unconformably overly the Aral Group. The Paranoa Group is divided into two sequences. The lower is made of five psamitic and pelitic units, with the discontinuous São Miguel metaconglomerate at the base. The upper sequence comprises four mostly pelitic and carbonatic units, with less important psamitic layers. The rocks have been metamorphosed to the biotite zone of the greenschist facies. Deformation is represented by an earlier phase of tight to isoclinal folding with axial-plane schistosity, possibly coeval with large nearly N-S trending thrusts verging towards the east. These structures are refolded by asymmetric to reverse chevron folds with north-south axial-plane crenulation cleavage. The latest phases are of SW plunging open folds, and large vertical folds with sub-horizontal E-W trending axes. The lower psamo-pelitic sequence correlates with the unmetamorphosed Paranoá Group outcropping near Alto Paraíso de Goiśs, to the east of the study area. The dominantly pelitic and carbonatic upper sequence is equivalent to the Minaçu Formation described further to the northwest. Stratigraphic relations between these sequences and their natural division in easily recognized units allow their characterization as groups of formations conferring supergroup rank to the Paranoá.
\end{abstract}

RESUMO Na regiâo de Niquelândia-Colinas, Goiás, o Grupo Araf repousa discordantemente sobre o embasamento granito-gnáissico com restos da Formação Ticunzal. Constitui-se de uma unidade inferior de quartzitos e quartzitos feldspáticos com camadas conglomeráticas e uma unidade superior de metapelitos carbonáticos, calcixistos, clorita xistos e lentes de mármore, com paragêneses típicas da fácies xisto verde. Em mapa, além do arqueamento geral determinado pelo alto estrutural do embasamento, observam-se dobras assimétricas, cujo eixo cai $5-20^{\circ}$ para $S 20 \mathrm{~W}$, e que representam fase de deformação anterior à deposiçăo do Grupo Paranoá. Este grupo sobrepóe-se em discordância ao Grupo Araf e consiste em duas seqũências, sendo a inferior, com cinco unidades mapeáveis, dominantemente psamo-pelftica. A superior consiste em quatro unidades mapeáveis, nas quais se sobressaem camadas pelito-carbonáticas, com menor contribuição psamítica. O metamorfismo atingiu a zona da biotita da fácies xisto verde. As deformaçōes sāo representadas por uma primeira fase de dobras apertadas a isoclinais com xistosidade de plano axial, provavelmente coeva aos grandes empurröes voltados para leste; sucede-se uma fase de dobras angulares assimétricas até inveresas, de direção submeridiana, com clivagem de crenulação de plano axial; as últimas fases sảo representadas por dobras abertas com caimento para S50W e amplas dobras verticais de eixo E-W sub-horizontal. A seqüëncia psamo-pelítica inferior corresponde ao Grupo Paranoá não metamórfico exposto na região de Alto Paraíso de Goiás. A seqüência superior é equivalente à Formação Minaçu. As relaçōes entre essas seqüências e sua divisão natural em unidades facilmente reconhecidas e de ampla distribuição na área autorizam antever sua hierarquizaçāo em grupos de formaçōes, corfferindo ao Paranoá o status de supergrupo.

INTRODUÇÃo No presente trabalho é apresentada uma síntese da geologia das unidades metassedimentares proterozóicas aflorantes nas bacias dos rios Bagagem e Tocantinzinho, afluentes da margem direita do Tocantins, nos municípios de Niquelândia e Cavalcante, Goiás. Ênfase é dada à estratigrafia do Grupo Paranoá, cujas rochas ocupam largas porçöes da área, e, em particular, ao esclarecimento das relações estratigráficas da seqüência de metassedimentos carbonatados, pelíticos e psamíticos integrante de ampla faixa de afloramentos que se estende por cerca de $300 \mathrm{~km}$, desde a confluência dos rios Tocantins e Paranã até o Distrito Federal (Fig. 1).
Essas rochas têm sido atribuídas a diversas unidades litoestratigráficas proterozóicas. Barbosa et al. (1969). consideraram-nas pertencentes à Formação Paraopeba do Grupo Bambuí, no sentido preconizado por Braun (1968), embora tenham inclứdo parte delas no Grupo Araxá e na Formação Traíras do Grupo Araí. A correlação com o Grupo Bambuŕ foi mantida em vários dos trabalhos subseqüentes, como, por exemplo, Schobbenhaus et al. (1975), Marini et al. (1977), Araújo \& Alves (1979) e Drago et al. (1981).

O registro da ocorrência de paraconglomerado na margem direita do Rio Tocantins, correlacionado com a Formação 


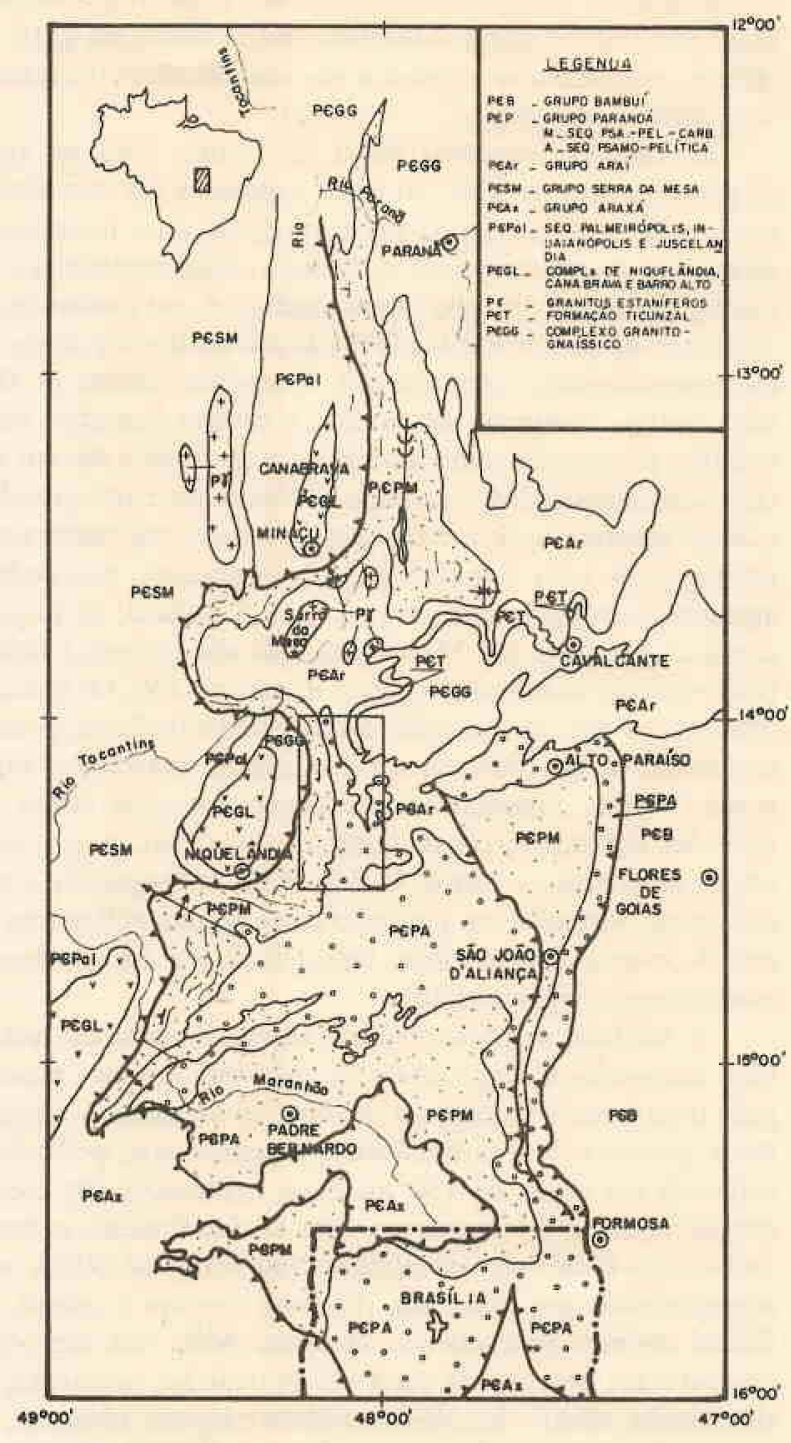

Figura 1 - Distribuição das seqüências psamo-pelítica e psamo-pelito-carbonática do Grupo Paranoá na região central de Goiás. O retângulo assinala a área representada na figura 2

Jequitar, base do Grupo Bambuí, levou Dardenne et al. (1978) a concluir que as camadas pelito-carbonáticas sotopostas seriam equivalentes ao Grupo Paranoá (segundo a redefinição de Dardenne 1978) ou pertencentes à Formação Traíras. A partir desta constatação, a seqüência passou a ser considerada, em princípio, como uma fácies pelito-carbonatada do Grupo Paranoá (Marini et al. 1978, 1979; Dardenne 1981), face às acentuadas diferenças em relaçåo às unidades detríticas que caracterizam o grupo na regiāo de Alto Paraíso de Goiás-São João d'Aliança. Jă Braun (1980) correlacionou a seqüência com as camadas superiores do Grupo Araí, denominando-a Grupo D e situando-a estratigraficamente acima dos grupos C (Traíras) e B (Paranoá), e abaixo do F (Bambuń).

A individualização da seqüência foi formalizada por Marini e Fuck (1981), com a denominação Formação Minaçu, posicionando-a abaixo do Grupo Bambuí, tomado este segundo a redefinição proposta por Dardenne (1978). Como as relaçōes de contato com o Grupo Paranoá não eram conhecidas com detalhe suficiente, Marini \& Fuck (1981) não descarta- ram a possibilidade de equivalência lateral com o referido grupo, aventando ainda a hipótese de que ambas as sequiênciạs venham a ser reunidas num mesmo grupo ou supergrupo de unidades litoestratigráficas.

A proposição da Formação Minaçu foi questionada por Magalhães (1982), por julgar que suas rochas nada mais seriam que a continuação lateral do Grupo Paranoá, tal como caracterizado nas imediações do Alto Paraíso de Goiás (Dardenne et al. 1978). Visando dirimir a controvérsia, foi encetado, em 1984, o levantamento geológico (escala 1:50.000) da área abrangida pela metade oriental da Folha Niquelândia $\left(14^{\circ}-14^{\circ} 30^{\prime}\right.$ latitude sul, $48^{\circ}-48^{\circ} 15^{\prime}$ longitude oeste), com a participação dos alunos formandos do Curso de Geologia da Universidade de Brasilia*, na esperança de que, ali, as relações estratigráficas da seqüếncia em questão pudessem ser devidamente esclarecidas.

ESTRATIGRAFIA Na área estudada, ocorre exposição relativamente restrita de rochas granito-gnáissicas com restos da Formação Ticunzal, que constituem o substrato regional das formações proterozóicas mais jovens representadas pelos grupos Araí e Paranoá. Em termos geotectônicos, a área situa-se no limite ocidental da Faixa Brasília, onde as rochas que a integram se acham sobrepostas por gnaisses do embasamento através de importante falha de cavalgamento de direção meridiana e vergência para leste.

As rochas granito-gnáissicas As rochas granito-gnáissicas ocupam o canto nordeste da área, formando um alto estrutural regional de forma ovalada, circundado pelos metassedimentos do Grupo Araí. Além disso, aparecem em estreita faixa de afloramentos, tectonicamente sobreposta às unidades superiores do Grupo Paranoá, no limite oeste da área mapeada (Fig. 2).

Os gnaisses são ortoderivados e representam sobretudo granitos e granodioritos deformados e recristalizados em condiçōes de fácies anfibolito de alta temperatura, conforme se atesta pela paragênese quartzo + ortoclásio + plagioclásio (An f́ndice A $_{20-30}$ ) + biotita I granada. A textura é média a grossa, eventualmente marcada pela presença de megacristais centimétricos de feldspato. As rochas são foliadas, raramente bandadas, mas tipos maciços aparecem às vezes. Veios pegmatíticos (quartzo + feldspato + moscovita \pm turmalina) e aplíticos são comuns. Recomposição mineralogica de mais baixo grau é freqüente, sendo representada pela microclinização do ortoclásio, pela substituição de feldspatos por moscovita, por saussuritização do plagioclásio e pela cloritização da biotita e da granada. Texturas cataclásticas e filoníticas são comuns. Milonito gnaisses e filonitos são especialmente importantes na zona de cavalgamento presente no limite oeste da área. Mostram uma foliação cataclástica crenulada com porfiroclastos estirados de quartzo e feldspato.

A idade dessas rochas não é conhecida com segurança. As poucas determinaçōes geocronologicas obtidas em áreas vizinhas fornecem is 6 cronas $\mathrm{Rb}-\mathrm{Sr}$ de referência com cerca de 2.000 Ma (Hasui et al. 1980, Drago et al. 1981). Na regiáo

\footnotetext{
* Alunos participantes: Ana Cristina Veríssimo dos Santos, Anísio Terra Machado da Costa, Benedito Eliazar de Andrade, Carlos Henrique Bernardi Pereira, Cesar Atsushi Ushirobira, DElzio de Lima Machado Júnior, Eduardo Pinto Fernandes, Gema Ribeiro Olivo, Jose Botelho Nete, Jose Guilherme Rodrigues da Silva, Jose Luiz de Miranda, Luiz Carlos de Lima, Luís Mauro Gomes Ferreira, Marcos Pimentel Mendes, Mário Mota Camara, Marlene Aparecida Morceli, Renato Ferreira, Sérgio da Silva Araújo, SÉrgio Santa Rita de Queiroz e Wilderaldo José Ancheschi.
} 
do Rio Preto, a noroeste da área, Reis Neto (1983) obteve retas de referência indicando idades arqueanas. $\mathrm{O}$ baixo alinhamento dos pontos analíticos, entretanto, empresta pouca confiabilidade às idades determinadas. As idades $\mathrm{K}$-Ar em minerais geralmente giram em torno de 500-600 Ma. Trata-se de valores mínimos, relativos ao último resfriamento das rochas da região (Drago et al. 1981).

A Formação Ticunzal Restos da Formação Ticunzal acham-se preservados da erosão pré-Araí em calhas sinclinais e zonas abatidas por falha. Em geral, a pequena extensão e a precariedade das exposições impedem sua cartografia, exceto ao norte de Colinas, onde foi mapeada uma faixa expressiva no sopé da chamada Serra das Trocas (Fig. 2). As rochas mais características da formação são xistos grafitosos, podendo a grafita representar cerca de $15 \%$ em volume da rocha em certos casos. Os termos mais freqüentes são moscovita-quartzo xistos, com proporçōes menores de grafita, biotita, feldspato e granada. Ocasionalmente, os xistos contêm teor elevado de turmalina, dando margem ao aparecimento de turmalina-moscovita-quartzo xisto e turmalina xisto. Camadas pouco espessas de quartzitos intercalam-se aos xistos. Muito comuns são intercalaçōes de xistos e biotita gnaisses, principalmente em direção à base do pacote. Os gnaisses são finos a médios, de cor cinza, e costumam apresentar numerosos veios de pegmatitos. A presença desses gnaisses dificulta muito a separação das rochas granito-gnáissicas, sobretudo em vista da escassez de affloramentos, impedindo o traçado mais preciso dos contatos entre as duas unidades.

As rochas da Formação Ticunzal são polideformadas e polimetamórficas. A xistosidade principal, que transpõe estruturas planares de deformações anteriores, orienta-se proximo de N5OE, 45NW. Apresenta-se crenulada, com clivagem do plano axial, sendo o eixo da crenulação (S20W/05) coincidente com o eixo da sucessão de anticlinais e sinclinais que caracterizam o Grupo Arấ na área. A paragênese associada a essas fases de deformaçâo é de fácies xisto verde (moscovita, quartzo, biotita, clorita), mas a presença de grãos reliquiares de granada e de feldspatos (plagioclásio 15-20\% An, microclínio) atesta a vigência de condiçōes anteriores de metamorfismo de fácies anfibolito. Essa inferência pode ser comprovada pelos estudos preliminares da cristalinidade da grafita, com auxflio de difratometria de raios- $X$, que indicam ter esse mineral, no caso dos xistos Ticunzal, provavelmente cristalizado sob temperaturas correspondentes à zona silimanita.

A idade da Formação Ticunzal precisa ser ainda determinada. A sugestão de que seja do Proteroz6ico Inferior e tenha sido deformada e metamorfizada no Ciclo Transamazônico (Marini et al. 1981, 1984 a,b) foi em parte confirmada por dados $\mathrm{Rb}-\mathrm{Sr}$ de Reis Neto (1983). Entretanto, os pontos analíticos representativos das amostras analisadas mostram-se dispersos no diagrama, tendo aquele autor traçado duas retas de referência, com cerca de 2.000 e $2.500 \mathrm{Ma}$, respectivamente, reunindo amostras tanto da Formação Ticunzal quanto das rochas granito-gnáissicas sotopostas.

Grupo Aral O Grupo Ará aflora de forma descontínua na porção leste da área estudada (Fig. 2). A base do grupo está exposta nas vizinhanças de Colinas, circundando o alto estrutural regional determinado pelo embasamento granito-gnáissico com restos da Formação Ticunzal. As relaçōes estratigráficas sắo caracteristicamente do tipo não-conformidade, com quartzitos, quartzitos conglomeráticos e metaconglomerados assentados sobre rochas graníticas, gnáissicas e xistosas previamente deformadas e metamorfizadas. Sucede-se um pacote de metapelitos carbonáticos, calcixistos e mármores impuros. Mais para sul, ocorrem sobretudo clorita filitos em geral calcíferos, aparentemente situados em posição elevada na coluna estratigráfica do grupo.

A camada mapeável basal do Grupo Araí na região (Fig.3) abrange cerca de $90 \mathrm{~m}$ de espessura e é representada por unidade de quartzitos finos a médios, com intercalações métricas a decamétricas de quartzitos conglomeráticos e metaconglomerados. $O$ topo dessa unidade $E$, em muitas seçōes, representado por quartzitos feldspáticos médios a grossos com metaconglomerados intercalados. Variaçōes laterais de fácies são comuns, mantendo-se, porém, o caráter psamítico característico da camada como um todo. Os quartzitos são em geral cinza-esbranquiçados, passando a róseos ou castanho-claros quando intemperizados, mal classificados e mal selecionados, normalmente com estratificação plano-paralela, mas podendo apresentar estratificação cruzada, até acanalada, de pequeno, médio e grande porte. Marcas de onda são comuns e indicam paleocorrente com sentido para o quadrante SW. Os metaconglomerados não têm posição estratigráfica definida, podendo apresentar-se em qualquer nível no pacote quartzítico. Em algumas seçōes, registram-se metaconglomerados basais que, além dos ubíquos seixos de quartzo e quartzito, podem conter seixos de gnaisses e xistos. Os seixos são subangulosos a arredondados, variando seu tamanho entre alguns milímetros e 30 $\mathrm{cm}$. A matriz é quartzítica fina a grossa e freqüentemente contém moscovita e hematita.

A unidade seguinte consiste essencialmente em metapelitos carbonáticos, com lentes de mármore impuro, passando para doloxistos e calcixistos em direção ao topo. A espessura desse pacote pelito-carbonático É desconhecida, podendo ser estimada em cerca de $150 \mathrm{~m}$. Boas exposiçōes sāo escassas devido ao fácil intemperismo. Nas rochas ffrescas, o teor de carbonatos $\&$ elevado (geralmente em torno de 50\%), sendo representados por dolomita, dolomita ferrosa e calcita, esta última também preenchendo fraturas. Além dos carbonatos, comparecem proporçōes variáveis de quartzo, moscovita, clorita, biotita, albita-oligoclásio, epídoto e alguma hematita.

Mais ao sul, nas áreas drenadas pelo Ribeirão Toconhão e no anticlinal desventrado pelo Rio Bagaginha (Fig. 2), ocorrem maiormente clorita filitos, quase sempre carbonáticos, além de afloramentos esparsos de sericita filitos prateados, filitos carbonosos, calcixistos, mármores impuros e quartzitos micáceos. A escassez e a descontinuidade dos afloramentos impossibilitaram a individualização cartográfica e o estabelecimento da sucessão estratigráfica dessas rochas bem como sua posição na coluna do Grupo Araí, embora seja lícito supor que ocupem situação mais elevada que aquelas dos arredores de Colinas.

Levando em conta as definiçōes propostas por Barbosa $e t$ al. (1969) e Dyer (1970 b), o pacote quartzítico basal faz parte da Formação Arraias enquanto as demais rochas se incluem na Formação Traíras, embora em outras áreas, como a nortenoroeste de Cavalcante, essa divisão ainda ofereça dúvidas, por terem sido observadas importantes intercalaçōes de calcixistos nos quartzitos da Formação Arraias (O.J. Marini, dados não publicados).

As paragêneses estudadas indicam metamorfismo t́pico da fácies xisto verde, correspondente à zona da biotita. As estruturas de deformação presentes na unidade são complexas em face da superimposiçẫo dos esforços que deformaram o Grupo Paranoá. As estruturas mais conspícuas das rochas do Grupo Araí foram cartografadas nos arredores de Colinas (Fig. 2) e são representadas por sucessão de anticlinais e sinclinais assimétricas (amplitude da ordem de $200 \mathrm{~m}$, distância 


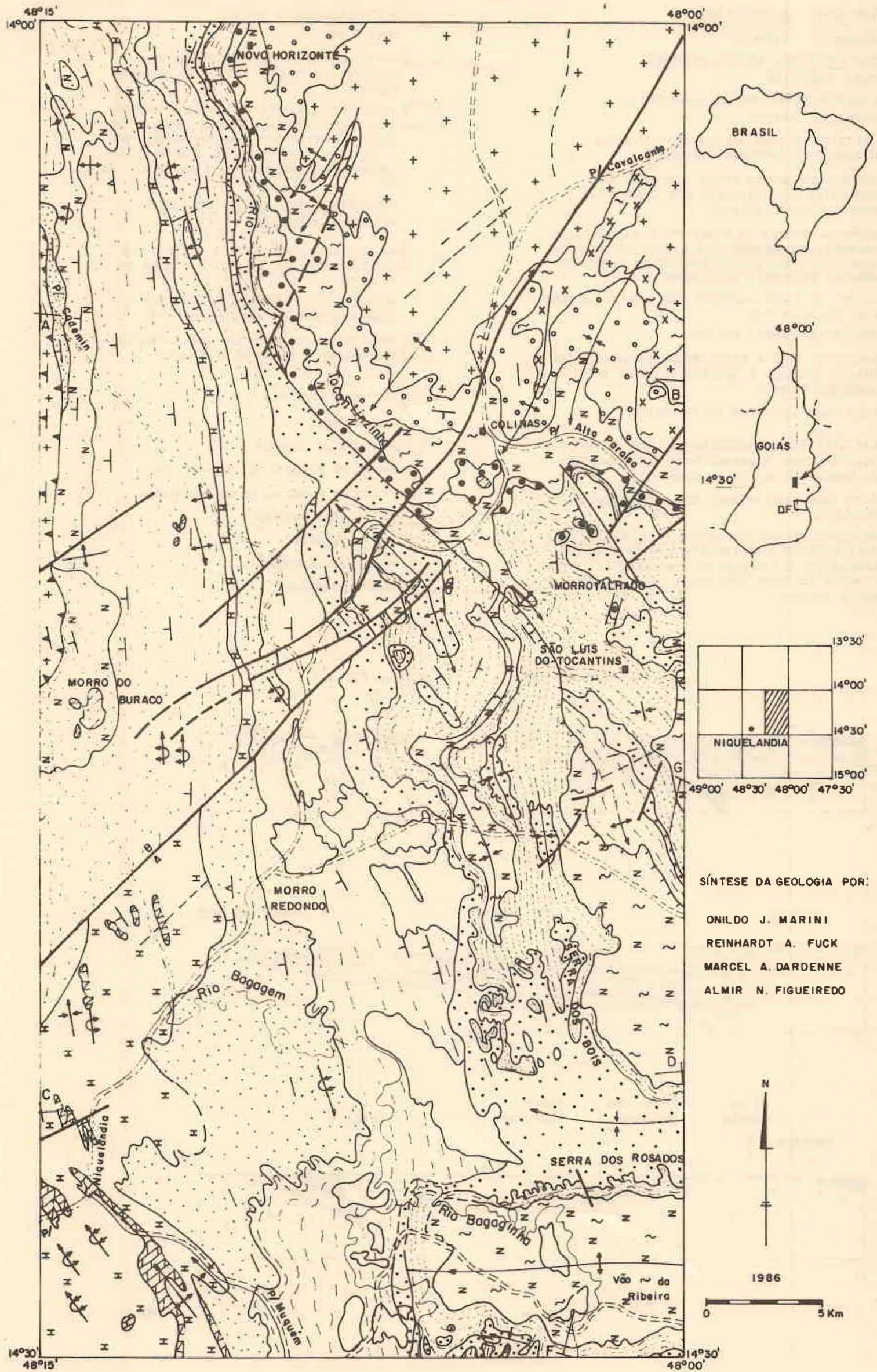


TERCIÁRIO - QUATERNÁRIO

-LATOSSOLO , LATERITA

PROTEROZÓICO MÉDIO/SUPERIOR

GrUDO PARANOÁ

SEQUUENCIA PSAMO-PELITO CARBONÁtICA

(FORMACGAOO MINACYU)

$\therefore$ I-QUARTZITO FELOSPÁTICO COM INTERCALAÇŌES DE METASSILTITO CARBONOSO RÍTMICO.

2. H.MÁRMORE DOLOMÍTICO RÓSEO A BRANCO, COM CONOPHYTON, INTERDIGITADO COM QUARTZITO FRIÁVEL E FILITO RÍTMICO

6-sequiencia rítmica de quartzito e filito Ginza Finamente acamadados, COM bancos MÉtricos DE QUARTZITO CINZA MAGICO E PEQUENAS LENTES DE MÁRMORE SILICOSO E METACHERT

I F_CALCIFILITO, FILITO CALCÍFERO COM LENTES DE MÁRMORE CALCAREMÍTICO seqüÉnCIA pSAMO-pelítica

E-QuaRtzito Fino a mÉdio, BRANCO, COM EstratiFICAGÃo CRUZADA E INTERCALAGOEES DE FILITO CARBONOSO RITHICO.

- - D.FILITO QUÁRTZOSO RICO EM MAGNETITA.

- C_quartzito fimo a méolo macigo com estratifi CACÁo CRUZADA, PASSAMDO PARA INTERCaLACÉES DE QUARTZITO E FILITO CARBONOSO.

D-Filito carbonoso rítmico com intercalagóes oe QUARTZITO.

- a paraconglomerado com seixos de mármore, ouartZITO, QUARTZO E METASSILTITO, MATRIZ ARGILO CARBOMÁTICA E LAMELAS DE ESPPECULARITA, INTERCALACÓES DE QUARTZITO CALCIFERO E FILITO CARBONOSO RITMICO.
PROTEROZÓICO MÉDIO

Grupo ARAI

2 CALCIXISTO, METAPELITOS CARBONÁtICOS, CLORITA - XISTO, COM LENTES DE MÁRMORE IMPURO.

- O quartzito feldospático médio a grosso COM ESTRATIFICACGÃO CRUZADA, MARCAS DE ONDA E LENTES DE CONGLOMERADOS; QUARTZITO PURO, FINO A MÉDIO, COM INTERCALAGōes de CONGLOMERADO, LOCALMENTE BaSAL.

PROTEROZÓICO INFERIOR (?) FORMAĞ̃Ó TICUNZAL

- - micaxisto, gRAFITA XISTO E gNaISSE COM INTERCALACOES DE QUARTZITO E VEIOS DE PEGMATITO

ARQUEANO/ PROTEROZÓICO INFERIOR COMPLEXO GRANITO - GNÁISSICO

+ GNAISSE GRANODIORÍTICO COM INTRUSÖES gRANÍTICAS E VEIOS DE PEGMATITO.

--- contATO geológico

- XISTOSIDADE

Y atitude de camada

* traço de plamo axial oe sinclinal

X traģo de plano axial de anticlinal

FALHA INDISCRIMINADA

FAL HA INVERSA

Falma de EMPURRāo

SEçĀo geOLóaICA
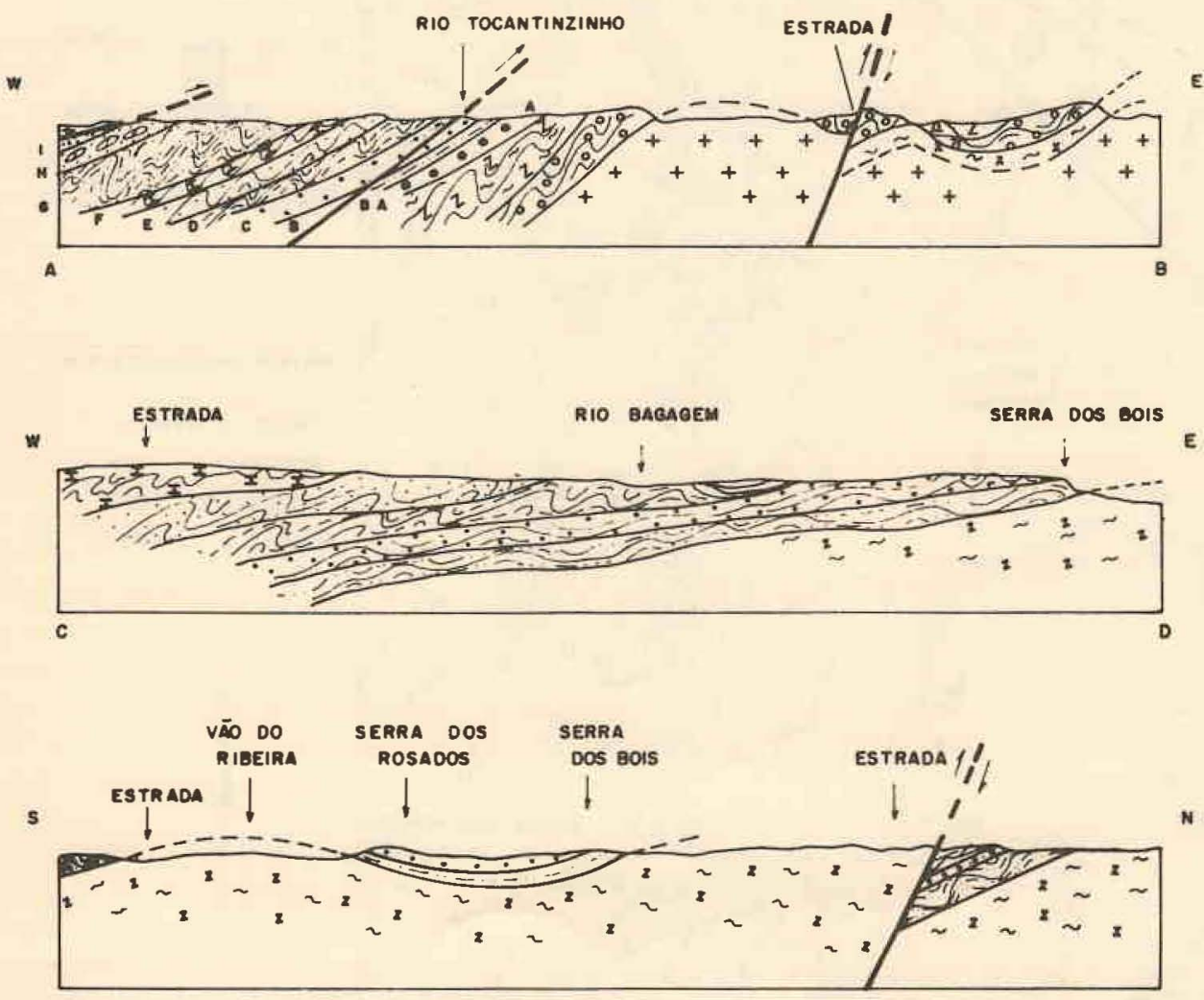

F



MAMAOA. 
entre charneiras cerca de $2 \mathrm{~km}$ ), com plano axial de forte mergulho para NW e eixo caindo $5-20^{\circ}$ S20W. Essas dobras não são reconhecidas no Grupo Paranoá e, como deformam uma xistosidade, pode-se concluir que o metamorfismo principal do Grupo Araí e pelo menos duas das fases de deformação que o afetaram antecedem a deposição do Grupo Paranoá.

A idade do Grupo Araí não está ainda estabelecida com precisão. Determinaçōes isotópicas pelo método $\mathrm{Rb}-\mathrm{Sr}$ em rochas metavulcânicas da base do grupo, coletadas na região de Cavalcante-Nova Roma, a nordeste da área estudada, resultaram em iś6crona de referência com 1.170 Ma, Ro=0,710. Segundo Tassinari et al. (1981), esse valor parece refletir a Época do metamorfismo sofrido pelas rochas. Reis Neto (1983) obteve isócrona de referência com $1.140 \mathrm{Ma}$ $(\mathrm{Ro}=0,712)$ em metavulcânicas das vizinhanças de Teresina, a leste de Cavalcante. No mesmo diagrama, além da isócrona referida, o autor traçou duas retas paralelas com idades aproximadas de $550 \mathrm{Ma}$ e razões iniciais elevadas. Ainda, a partir de calcixistos, obteve reta de referência de $470 \mathrm{Ma}$ $(R o=0,765)$, levando-o a concluir que o Grupo Araí sofreu importante homogeneizaçã̉o isotópica durante o Ciclo Brasiliano, fato que parece confirmado pelas idades aparentes de 580 a 670 Ma obtidas pelo método K-Ar em metavulcânicas. Marini et al. (1986) referem evidências de campo e geoquímicas indicando possível contemporaneidade e consangüinidade entre metarriólitos do Grupo Araí e o Granito Pedra Branca, na região de Nova Roma. O granito mencionado forneceu isócrona $\mathrm{Rb}-\mathrm{Sr}$ com cerca de $1.400 \mathrm{Ma}$, sobre a qual se localiza ponto analítico de metarriólito, indicando, caso não se trate de mera coincidência, idade similar para o Araí (Marini et al. 1986). Em conclusão, os dados disponíveis permitem sugerir idade provável da ordem de $1.400 \mathrm{Ma}$ para o Grupo Araí, ao passo que seu metamorfismo teria ocorrido há cerca de 1.150 $\mathrm{Ma}$, com homogeneização isotópica parcial superimposta durante o Ciclo Brasiliano.

Grupo Paranoá O Grupo Paranoá cobre cerca de 3/4 da área estudada (Fig. 2), sobrepondo-se em discordância ao Grupo Araf. É constiturdo por rochas metassedimentares predominantemente psamíticas na porção basāl e psamo-pelitocarbonáticas no topo, divididas em nove unidades mapeáveis que correspondem a formaçöes a serem definidas (com a indicação de seções-tipo) e denominadas em trabalho de cunho mais regional, em preparação. Por ora, são distinguidas informalmente por letras.

$\mathrm{Na}$ seqüência psamítica inferior foram separadas cinco unidades mapeáveis (Fig. 2, 3):

- A unidade A é caracterizada por metaparaconglomerado constituído de seixos angulosos e subarredondados de quartzo, quartzito fino, metassiltito e calcixisto envolvidos por matriz quartzosa grossa, rica em carbonatos, de cor cinza-esverdeada, na qual se destacam freqüentes lamelas de especularita. Variaçöes para quartzitos e metassiltitos carbonáticos e intercalações de filitos carbonosos rítmicos estão presentes em muitos afloramentos. O metaparaconglomerado geralmente exibe aspecto maciço, em poucas exposições verificando-se estruturas planares de estratificação. A espessura máxima da unidade não excede $80 \mathrm{~m}$ e, apesar de descontínua a nível regional, constitui um marco importante na estratigrafia das unidades proterozóicas da região, por assinalar a base do Grupo Paranoá, repousando em discordância angular e erosiva sobre as unidades dobradas e metamorfizadas do Grupo Araí. Foi originalmente descrito a poucos quilômetros a leste de Colinas sob a denominação de Conglomerado São Miguel (Braun 1968, Barbosa et al. 1969, Dyer 1970 a).

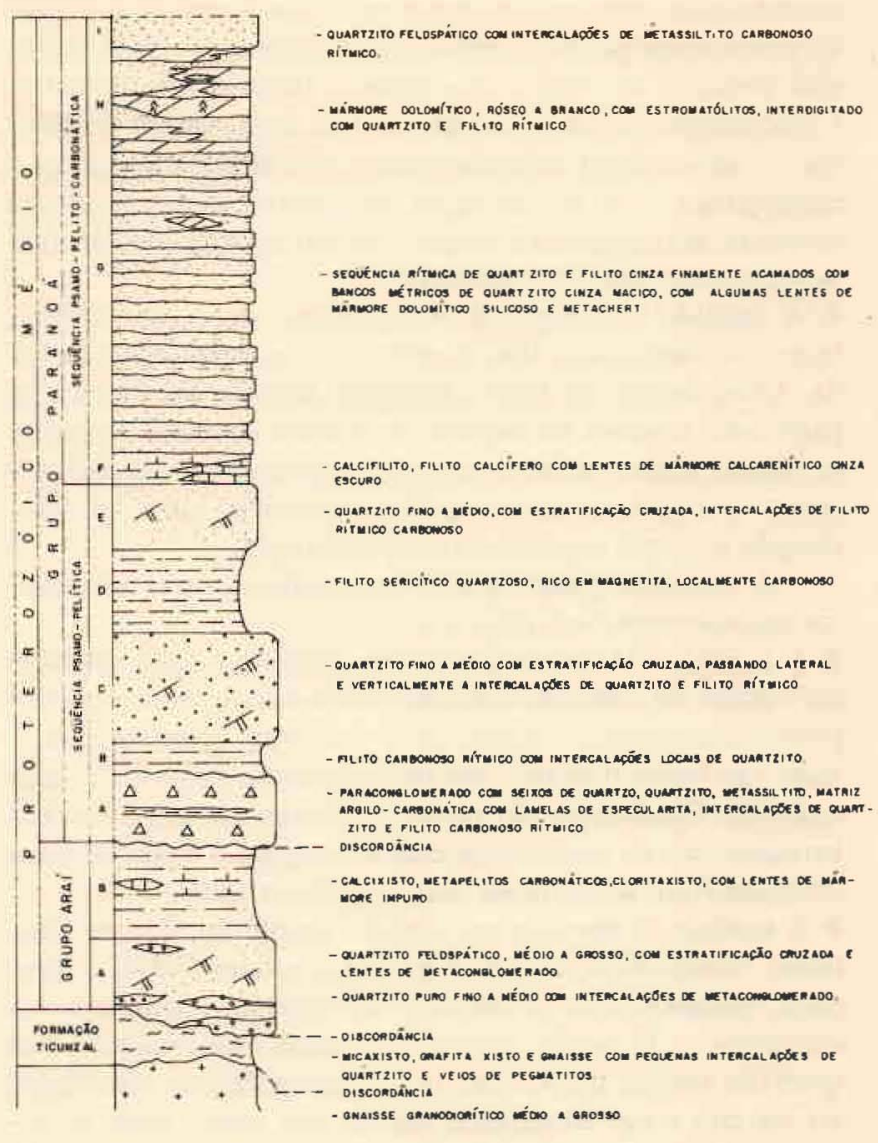

Figura 3 - Coluna litoestratigráfica dos grupos Arat e Paranoá na região de Colinas-Niquelândia

- A unidade B consiste em filito carbonoso rítmico, localmente calcífero, com intercalaçöes pouco espessas de quartzito e variaçōes para metassilito. Intemperizado, adquire caracteríticas cor vermelho-tijolo, desagregando em placas decimétricas similares a fragmentos de telha. Na regiāo da Serra dos Bois e no anticlinal desventrado do Rio Bagaginha (Fig. 2), em que o Conglomerado São Miguel está ausente, a unidade constitui a base do Grupo Paranoá. Em outros locais não foi possível fazer a separação entre as unidades $A$ e $B$ ou mesmo identificar a B, visto ocorrer, por via de regra, em encostas íngremes às faldas de serras mantidas pelos quartzitos da unidade $\mathrm{C}$, onde são raros os afloramentos.

- A unidade C é composta de quartzito médio a fino, estratificado em bancos métricos maciços ou com estratificação cruzada. Lateral e verticalmente há passagem para camadas em que se observam intercalações de quartzito e filito carbonoso. $\mathrm{O}$ conjunto apresenta variações significativas de espessura. $\mathrm{Na}$ área de Colinas-São Luís do Tocantins, alcança mais de uma centena de metros, enquanto mais a sul não excede $40 \mathrm{~m}$ de espessura. Esta unidade desempenha importante papel no relevo regional por sustentar os maiores altos topográficos, como as serrras dos Bois, dos Rosados etc.

- A unidade D é formada por sericita filito quartzoso, localmente carbonoso na base, caracterizado pela presença comum de octaedros milimétricos de magnetita. Caráter rítmico é impresso pela alternância de finos leitos originalmente argilosos, sflticos e, mais raramente, arenosos. Trata-se de importante 
camada-guia, com aspecto único no Grupo Paranoá. É definida pelo caráter pelítico e pela marcante homogeneidade litologica presente em toda a sua extensa faixa de afloramentos. Caracterizam-na também a ausência de intercalaçōes psamíticas ou carbonáticas individualizadas, ritmicidade milimétrica a centimétrica, cor de alteração vermelho-tijolo, a presença constante de magnetita e o típico padrão de drenagem dendrítico fino observado em aerofotos.

- A unidade E compõe-se de quartzito localmente friável, branco a cinza-claro, fino a médio, com estratificação cruzada. Intercalações de filito carbonoso rítmico são comuns na parte mais superior da camada. A unidade constitui o topo da sequiência psamo-pelítica, sobre ela repousando concordantemente a seqüência psamo-pelito-carbonática que, na área, compõe a porção superior do Grupo Paranoá.

A sequiência psamo-pelito-carbonática compreende quatro unidade mapeáveis (Fig. 2, 3):

- A unidade F é representada por calcifilito e filito calcífero com lentes de mármore calcítico cinza-escuro. O mármore é predominantemente calcarenítico, conforme pode ser observado nas lentes maiores expostas na porção sudoeste da área estudada. Calcilutitos são também comuns, enquanto brechas lamelares são de menor importância. Pequenas lentes de chert manganesífero foram observadas em vários locais.

- A unidade G abrange um espesso pacote de ritmitos finamente acamadados, constituídos por quartzito friável e filito cinza carbonoso que se alternam em camadas centimétricas a decimétricas. O ritmito contém freqüentes bancos métricos de quartzito maciço cinza, que, por se apresentarem ressaltados no terreno e nas fotografias aéreas, são muito úteis na reconstrução das dobras impressas no pacote.

- A unidade $\mathrm{H}$ compõe-se de mármore dolomítico interdigitado com quartzito branco friável e filito rítmico. O mármore é branco, róseo ou cinza-claro e caracteriza-se pela presença comum de estromatólitos colunares (Conophyton). As camadas dolomíticas têm espessura variável de poucos metros a algumas dezenas de metros. Apenas as que se expóem no Morro do Buraco puderam ser individualizadas na escala de trabalho (Fig. 2).

- A unidade I consiste em quartzito feldspático, com intercalaçōes de metassiltito carbonoso rítmico. Corresponde à camada aflorante mais superior do Grupo Paranoá na área, tendo, juntamente com a unidade $H$, sido cavalgada por milonito gnaisses e filonitos derivados dos granito-gnaisses do embasamento (Fig. 2).

$\mathrm{Na}$ área estudada, os metassedimentos do Grupo Paranoá mostram paragêneses minerais típicas da fácies xisto verde baixo, observando-se um discreto aumento do grau metamórfico em direção ao canto noroeste da área onde a presença de biotita é comum e onde, de modo geral, as rochas sofreram recristalização mais acentuada, com desenvolvimento de biotita-clorita-moscovita xistos finos a partir de rochas pelíticas.

Várias fases de deformação foram reconhecidas nos metassedimentos Paranoá. A primeira fase $\varepsilon$ representada por xistosidade bem desenvolvida, sobretudo nos materiais de natureza pelítica, associada a dobras apertadas ate isoclinais. As poucas medidas do eixo efetuadas mostram direções submeridianas. Essas estruturas foram redobradas por micro-, mesoe megadobras angulares assimétricas, inclinadas até inversas, de tipo chevron, que correspondem à fase mais comumente reconhecida nos afloramentos e nas fotografias aéreas. A essas dobras se associa conspícua clivagem de crenulação que transpōe a xistosidade mais antiga. A direção geral é submeridiana, infletindo gradativamente para $\mathrm{N} 30-40 \mathrm{~W}$, como se verifica a oeste do Rio Bagagem. A vergência é voltada para leste, rumo ao Cráton São Francisco. A terceira fase, observada sobretudo em rochas quartzíticas da porção sul da área, consiste em dobras mesoscópicas normais, abertas, com eixo de direção próxima de N50E e caimento para SW; localmente registra-se a presença de clivagem de fratura restrita às zonas axiais das dobras. A cultima fase ê representada por amplas dobras suaves e abertas, com eixo E-W sub-horizontal; a essa fase pertencem o anticlinal desventrado do Rio Bagaginha e o sinclinal assinalado entre as serras dos Rosados e dos Bois, na porção sudeste da área estudada (Fig. 2).

Além das dobras, vários conjuntos de falhas desempenham papel de relevo na estruturação regional. Destacam-se, por sua importância, a falha inversa perlongada pelo Rio Tocantinzinho, responsável pela omissão e repetição de camadas, principalmente da porção basal do Grupo Paranoá, e a falha de empurrão reconhecida no limite ocidental da área estudada (Fig. 2). Esta última, que assinala o cavalgamento do embasamento granito-gnáissico por sobre o Grupo Paranoá, parece estar relacionada à primeira fase de deformaçăo que afetou o referido grupo. Seus filonitos exibem crenulaçōes e microdobras superimpostas de direçẩo coincidente com a segunda fase de dobramento impressa nos metassedimentos Paranoá. Dignos' de registro são também os sistemas de falhas normais de direção NW-SE e NE-SW. Ao altimo pertencem as falhas registradas nas vizinhanças de Colinas e a falha rotacional identificada na porção central da área, que determina importante alargamento da faixa de afloramentos das unidades $\mathrm{D}, \mathrm{E}$ e F do Grupo Paranoá no bloco situado a sudeste da falha (Fig. 2).

O exame da coluna estratigráfica estabelecida para o Grupo Paranoá na área estudada mostra que a seqüência psamo-pelítica corresponde ao pacote inferior do Grupo Paranoá exposto na região de Alto Paraíso de Goiás, onde se observa a mesma sucessão litoestratigráfica, porém isenta de metamorfismo e com deformaçōes muito suaves (Dardenne \& Faria 1986). Já a seqüência psamo-pelito-carbonática, que constitui a porção superior do Grupo Paranoá na área, equivale à Formação Minaçu descrita na regiāo homônima, onde aparece com características quase idênticas, até no que diz respeito a deformações e metamorfismo, embora com uma camada a mais no topo (Marini \& Fuck 1981). Convém registrar que nas vizinhanças de Minaçu a base dos metassedimentos Paranoá é constituída pelos quartzitos equivalentes à unidade $\mathrm{E}$ cartografada na área do presente trabalho. Esta a razão pela qual foi incluída na Formação Minaçu. Entretanto, a seção mais completa do Paranoá exposta na área Colinas-Niquelândia, bem como a natureza dos conjuntos litoestratigráficos que o compõem, indica ser mais adequada e natural a inclusão dos quartzitos mencionados na seqüência psamo-pelf́tica inferior. Dessa forma, o conjunto superior inicia-se na primeira unidade carbonática por representar uma mudança mais significativa da sedimentação na bacia Paranoá. Em conseqüência, é sugerida uma pequena modificação na definição original da Formação Minaçu.

Por outro lado, a comparação da seqüência psamo-pelito-carbonática de Colinas-Niquelândia com as unidades superiores do Grupo Paranoá descritas na região de Alto Paraíso de Goiás indica a presença de importantes variações de fácies entre ambas as áreas. Em Alto Parafso, dominam largamente as camadas resultantes de sedimentação clástica e as camadas carbonáticas são pouco desenvolvidas (Dardenne \& Faria 1986). Constata-se, assim, que, em direção a oeste, diminui a espessura das unidades arenosas, aumenta a importância dos clásticos finos e amplia-se a sedimentação carbonática na parte superior da coluna estratigráfica, indicando um ligeiro 
aprofundamento da bacia de deposição na mesma direção. É importante registrar, também, que a expansáo da bacia $\mathrm{Pa}$ ranoá para noroeste ocorreu por ocasiâo da deposição dos quartzitos da unidade $\mathrm{E}$, que transgridem por sobre o substrato representado pelos grupos Araf e Serra da Mesa na direção da região de Minaçu.

A idade do Grupo Paranoá $\varepsilon$ ainda objeto de especulações. As indicações existentes baseiam-se nas relaçōes conhecidas com as unidades litoestratigraficas vizinhas e nas estruturas estromatolíticas presentes em suas rochas. Tais estruturas, especialmente as laminaçōes convexas tipo Conophyton encontradas nas camadas dolomíticas, inclusive na área estudada, são consideradas restritas ao final do Proteroz6ico Médio, entre 950 e $1.350 \mathrm{Ma}$ (Dardenne et al. 1972, Cloud \& Dardenne 1973). Por outro lado, considerando que o Grupo Paranoá assenta em discordância sobre as rochas previamente dobradas e metamorfizadas do Grupo Araf, e, a crer na sugestão de que o metamorfismo desse grupo tenha ocorrido há cerca de $1.150 \mathrm{Ma}$ (Tassinari et al. 1981), a sedimentaçăo $\mathrm{Pa}$ ranoá pode ter-se iniciado ao redor de 1.000-1.100 Ma atrás. Já o limite superior do grupo $\varepsilon$ marcado pela discordância erosiva que o separa do tilito Jequitaf ou da Formação Sete Lagoas do Grupo Bambuf. A idade do Jequitaí não está firmemente estabelecida, não se sabendo a qual das três glaciaçōes do Proterozóico Superior está relacionado. Os indícios existentes, entretanto, permitem supor como candidato mais plausfvel a segunda glaciação da referida era, cuja idade $\varepsilon$ estimada em 700-800 Ma (Dardenne 1981, Marini et al. 1984 a,b). Dessa forma, $\varepsilon$ provável que a sedimentação do Grupo Paranoá se tenha iniciado por volta de 1.100-1.000 Ma atrás e se encerrado anteriormente há $800 \mathrm{Ma}$. Os dados disponfveis indicam que deformaçōes e metamorfismo estão relacionados à Orogênese Brasiliana, cujo ápice se deu entre 650 e 600 Ma atrás.

CONCLUSÃO Os trabalhos de cartografia geologica reportados na presente contribuição permitiram estabelecer claramente as relações estratigráficas entre os grupos Araf e Paranoá na área de Niquelândia-Colinas. A base do Grupo Paranoá, representada pelo Conglomerado São Miguel, ou, na ausência deste, por filito carbonoso rítmico, repousa em discordância angular e erosiva sobre as unidades previamente dobradas e metamorfizadas do Grupo Ará. A par disso, o levantamento de seçōes estratigráficas e sua correlação conduziram à conclusão de que, na área, o Grupo Paranoá é constitufdo por dois conjuntos de unidades metassedimentares mapeáveis: um basal, com importantes camadas psamíticas, e um superior, dominantemente pelítico, com significativa contribuição carbonática. A seqüência inferior corresponde à porção inferior do Grupo Paranoá exposta nas vizinhanças de Alto Paraíso de Goiás (Dardenne \& Faria 1986), onde, porém, É destitúda de metamorfismo. A seqüência superior equivale à Formação Minaçu (Marini \& Fuck 1981).

Dispőe-se, dessa forma, de elementos substantivos para o estabelecimento de correlaçōes entre as diveras áreas de exposição do Grupo Paranoá no Estado de Goiás e, sobretudo, de uma base sólida para sua adequada subdivisāo litoestratigráfica. As unidades cartografadas correspondem estritamente a formaçōes e sua associação natural permite o estabelecimento de dois grupos de formaçöes, que, por sua vez, rérnem-se numa unidade litoestratigráfica com a possível hierarquia de um supergrupo. Essas correlaçōes e subdivisões, bem como a nomenclatura apropriada decorrente, são objeto de trabalho atualmente em elaboração.

\section{REFERÊNCIAS BIBLIOGRÁFICAS}

ARAÚJO, V.A. \& ALVES, A.C. 1979. Projeto Canabrava - Porto Real. Goiânia, DNPM/CPRM, Relatório Final, 9v. (inédito).

BARBOSA, O.; BAPTISTA, M.B.; BRAUN, O.P.G.; DYER, R.C.; COTTA, J.C. 1969. Geologia e inventário dos recursos minerais da regiâo central de Goiás (Projeto Brasília). Brasília, DNPM, 148 p. (Geologia Básica 13, 1981).

BRAUN, O.P.G. 1968. Contribuição à estratigrafia do Grupo Bambuí. In: CONGR. BRAS. GEOL., 22, Belo Horizonte, 1968. Anais... Belo Horizonte, SBG. p. 155-166.

BRAUN, O.P.G. 1980. Revisão estratigráfica na área central de Goiás. In: CONGR. BRAS. GEOL., 31, Baln. Camboriú, 1980. Anais... Baln. Camboriú, SBG. v. 2, p. 705-719.

CLOUD, P.E. \& DARDENNE, M.A. 1973. Proterozoic age of Bambui Group in Brazil. Geol. Soc. Amer. Bull., 84(5):1673-1676.

DARDENNE, M.A. 1978. Sintese sobre a estratigrafia do Grupo Bambuí no Brasil Central. In: CONGR. BRAS. GEOL., 30, Recife, 1978. Anais... Recife, SBG. v. 2, p. 597-610.

DARDENE, M.A. 1979. Les minéralisations de plomb, zinc, fluor du Proterozoïque Superieur dans le Brésil Central. Avec une mise au point sur la chronologie du Précambrien brésilien. Paris, Univ. Paris VI. 251 p. (Thèse de Doctorat d'État (inédito).

DARDENNE, M.A. 1981. Os grupos Paranoá e Bambuí na Faixa Dobrada Brasília. In: SIMP. SOBRE O CRÁTON DO SÃO FRANCISCO E SUAS FAIXAS MARGINAIS, Salvador, 1979. Anais... Salvador, SME/SBG-Núcleo da Bahia. p. 140-157.

DARDENNE, M.A. \& FARIA, A. 1986. Estratigrafia do Grupo Paranoá na região de Alto Paraíso, Goiás. In: SIMP. GEOL. CENTRO-OESTE, 2, Goiânia, 1985. Ata... Goiânia, SBG/Núcleo Centro-Oeste. p. 65-71.

DARDENNE, M.A.; FARIA, A.; MAGALHÃES, L.F.; SOARES, L.A. 1978. O tilito de base do Grupo Bambui na borda ocidental do
Cráton São Francisco. Goiânia, SBG/Núcleo Centro-Oeste. p. 8587 (Bol. Informativo 7 e 8).

DARDENNE, M.A.; MELLO, S.M.G.; MOERI, E. 1972. Conophyton, um fóssil índex do Pré-Cambriano no Grupo Bambuí. Ciência e Cultura, 24(2): 199-203.

DRAGO, V.A.; PINTO. A.C.; MONTALVÃO, R.M.G.; SANTOS, R.O.B.; SIMÕES, M.A.; OLIVEIRA, F.C.; BEZERRA, P.E.L.; PRADO, P.; FERNANDES, C.A.C.; TASSINARI, C.C.G. 1981. Geologia. In PROJETO RADAMBRASIL. Folha SD. 22 Goiás. Rio de Janeiro, p. 27-300 (Levantamento de Recursos Naturais 25).

DYER, R.C. 1970a. Notas sobre o Conglomerado São Miguel, basal da Formação Paranoá. Rev. Escola de Minas, 28(1):27-30. Ouro Preto.

DYER, R.C. 1970b. Grupo Araí - um grupo de Metamorfitos do centro-leste de Goiás. Rev. Escola de Minas, 28(2):55-63. Ouro Preto.

HASUI, Y.; TASSINARI, C.C.G.; SIGA Jr., O.; TEIXEIRA, W.; ALMEIDA, F.F.M.; KAWASHITA, K. 1980. Datações Rb-Sr e KAr do Centro-Norte do Brasil e seu significado geológicogeotectônico. In: CONGR. BRAS. GEOL., 31, Balneário Camboriú, 1980. Anais... Balneário Camboriú, SBG. v. 5, p. 2659-2676.

MAGALHÃES, L.F. 1982. A Formação Minaçu: estratigrafia, tectônica e metamorfismo - discussão. Goiânia, SBG/Núcleo CentroOeste. p. 41-44 (Bol. Informativo 11).

MARINI, O.J.; BOTELHO, N.F.; MACAMBIRA, M.J.B.; PROVOST, A. 1986. Idade do Granito Pedra Branca (Goiás) e possiveis implicaçōes geotectônicas. In: SIMP. GEOL. CENTRO-OESTE, 2, Goiânia, 1985. Ata... Goiânia, SBG/Núcleo Centro-Oeste. p. 90-106.

MARINI, O.J. \& FUCK, R.A. 1981. A Formação Minaçu; estratigrafia, tectônica e metamorfismo. In: SIMP. GEOL. CENTRO OESTE, 1, Goiânia, 1981. Ata... Goiânia, SBG/Núcleos CentroOeste e Brasília. p. 716-745. 
MARINI, O.J.; FUCK, R.A.; DANNI, J.C.M.; DARDENNE, M.A. 1981. Evolução geotectônica da Faixa Brasília e do seu embasamento. In: SIMP. CRÁTON DO SÃO FRANCISCO E SUAS FAIXAS MARGINAIS, Salvador, 1979. Anais... Salvador, SME/SBG-Núcleo Bahia. p. 100-115.

MARINI, O.J.; FUCK, R.A.; DANNI, J.C.M.; DARDENNE, M.A.; LOGUERCIO, S.O.C.; RAMALHO, R. 1984a. As faixas de dobramentos Brasília, Uruaçu e Paraguai-Araguaia e o maciço mediano de Goiás. In: SCHOBBENHAUS, C.; CAMPOS, D.A.C.; DERZE, G.R.; ASMUS, H.E. coords. Geologia do Brasil. Brasília, DNPM. p. 251-303.

MARINI, O.J.; FUCK, R.A.; DARDENNE, M.A.; DANNI, J.C.M. 1984b. Província Tocantins. Setores Central e Sudeste. In: ALMEIDA, F.F.M. HASUI, Y. (coord.). O Pré-Cambriano do Brasil. São Paulo, Edgard Blücher. p. 205-264.

MARINI, O.J.; FUCK, R.A.; DARDENNE, M.A.; FARIA, A. 1977. Contribuição à geologia do Precambriano da porção central de Goiás. Rev. Bras. Geoc., 7(4):304-324.

MARINI, O.J.; FUCK, R.A.; DARDENNE, M.A.; TEIXEIRA, N.A. 1978. Dobramentos da borda oeste do Cráton do São Francisco. In: REUNIĀO PREP. SIMP. CRÁTON DO SÃO FRANCISCO E SUAS FAIXAS MARGINAIS, Salvador, 1977. Anais... Salvador, SME/SGB-Núcleo Bahia. p. 155-193 (Publ. Esp. 3).
REIS NETO, J.M. 1983. Evolução geotectônica da bacia do alto Tocantins, Goiás. São Paulo, Universidade de São Paulo, (Dissertação de Mestrado), 98 p. (inédito).

SCHOBBENHAUS, C.; RIBEIRO, C.L.; OLIVA, L.A.; TAKANOHASHI, J.T.; LINDENMAYER, Z.G.; VASCONCELOS, J. B.; ORLANDI, V. 1975. Carta Geológica do Brasil ao Milionésimo, Folha de Goiás SD. 22. Brasília, DNPM. $114 \mathrm{p}$.

TASSINARI, C.C.G.; SIGA Jr., O.; TEIXEIRA, W. 1981. Panorama geocronológico do Centro-Oeste brasileiro: soluções, problemática e sugestões. In: SIMP. GEOL. CENTRO-OESTE. 1. Goiânia, 1981. Ata... Goiânia, SBG/Núcleos Centro-Oeste e Brasília. p. 93116.

MANUSCRITO 470

Recebido em 30 de julho de 1987

Revisão aceita em 30 de novembro de 1987 